\title{
Organ procurement organization and university-based respiratory care program partnership to develop student internships
}

\author{
Nicholas R. Henry, MS, RRT-ACCS, RRT-NPS, AE-C $C^{1,2}$, Christopher J. Russian, Ph.D., RRT-NPS, RPSGT, RST, FAARC ${ }^{1}$,
} Micah Williams, BSN, RN, CPTC ${ }^{2}$, Ann Marie Pezzuto, BSRC, RRT²

\begin{abstract}
NR Henry, CJ Russian, M Williams, AM Pezzuto. Organ procurement organization and university-based respiratory care program partnership to develop student internships. Can J Respir Ther 2021;57:39-43. doi: 10.29390/cjrt-2020-055.

Introduction: Health care providers working as organ recovery coordinators (ORC) in the United States have diverse backgrounds and many of the skills needed for the position are obtained during on-the-job training. Some students in health care programs express interest in the organ procurement field but have limited experience and knowledge regarding organ procurement practices. In response to this, a partnership was developed between an undergraduate respiratory care $(\mathrm{RC})$ program and its local organ procurement organization (OPO) to develop and initiate an internship designed to educate students regarding organ procurement.

Approach: The 160-h internship was developed with collaboration between the OPO administration and faculty from the university RC program, which closely followed the OPO's formalized per diem ORC orientation model. Student reflective journals were qualitatively analyzed to determine the shared experiences during the OPO internships.

Findings: One RC student participated in the internship in 2017 and three RC students participated in 2019. The student interns actively participated in organ donor management in the critical care and surgical settings with the scheduled ORCs. Student progression of emotional competence and leadership were demonstrated throughout the internship.

Discussion: The OPO internship benefited RC students by providing opportunities for professional development that may not be available during their typical clinical rotations and strengthened their critical care skills and emotional competence.

Conclusion: Employment as an ORC is an emerging role for respiratory therapists. Offering educational opportunities such as internships in emerging roles promotes student development and autonomy while promoting the respiratory therapy profession.
\end{abstract}

Key Words: critical reflection; emotional competence; internship; clinical practicum; student development

\section{INTRODUCTION}

Many baccalaureate degree respiratory care $(\mathrm{RC})$ programs incorporate internship opportunities into their curriculum at affiliated institutions. Internships facilitate the transition of learning in the classroom to real world job experience [1] and has been shown to benefit students and employers hosting the internship [2,3]. RC student internships are conducted in a wide range of specialty areas.

An emerging role for respiratory therapists is employment as organ recovery coordinators (ORCs) for organ procurement organizations (OPOs). These federally designated organizations are tasked with the medical management of organ donors following consent, coordinating organ recovery for transplant, supporting donor families, and educating the public and health care community regarding organ donation within their federally designated service area. ORCs have diverse backgrounds consisting of nurses, paramedics, respiratory therapists, and various other trained health care employees. Respiratory therapists can utilize their ventilator management and critical care skills when evaluating patients for medical suitability of transplant and when medically managing the care of organ donors.

The Department of Respiratory Care at Texas State University (TXST) with the collaboration of the Texas Organ Sharing Alliance
(TOSA) developed an internship opportunity for students enrolled in the Bachelor of Science in Respiratory Care (BSRC) program. The 160-h internship allowed RC student interns (RC intern) to work closely with the ORCs when rounding on patient referrals located within intensive care units (ICUs) throughout Austin and the surrounding area, help to manage organ donors, and observe the recovery of organs in the operating room. While the faculty of the Department of Respiratory Care believe this novel internship will facilitate professional growth and development, the experiences of RC students participating in this type of internship is not known. The goals of this paper are to: $(i)$ describe the development of a RC student internship created with the collaboration between the Department of Respiratory Care at TXST and TOSA to serve as a model for other RC programs and (ii) explore the experiences of RC students participating in an OPO internship.

\section{METHODS}

The BSRC program at TXST requires students to perform two internships during the Spring semester of their senior year, one in the adult ICU and one in a specialty area of the student's choosing [4]. The specialty internship course is intended to build skills in an area that challenges student thinking and psychomotor abilities.

${ }^{1}$ Department of Respiratory Care, Texas State University, Round Rock, TX, USA

${ }^{2}$ Texas Organ Sharing Alliance, Austin, TX, USA

Correspondence: Nicholas R. Henry, 200 Bobcat Way., Department of Respiratory Care, Texas State University, Round Rock, Texas 78665. Tel: 512-7162689, Fax: 512-716-2805, E-mail: NH14@txstate.edu

Published online at https://www.cjrt.ca on 21 April 2021

This open-access article is distributed under the terms of the Creative Commons Attribution Non-Commercial License (CC BY-NC) (http:// creativecommons.org/licenses/by-nc/4.0/), which permits reuse, distribution and reproduction of the article, provided that the original work is properly cited and the reuse is restricted to noncommercial purposes. For commercial reuse, contact editor@csrt.com 
Development of a respiratory care OPO internship

Discussion of a RC internship with an OPO was first held during the summer of 2016 between the Chief Executive Officer (CEO) of TOSA and the Director of Clinical Education for the Department of Respiratory Care at TXST. It was the belief by both parties that an internship with an OPO would facilitate student growth and development of critical care management skills commonly performed by ORCs such as vasopressor titration, ordering of lab work, input and output calculation, and discussing medical suitability of transplant with transplant centers. The internship was developed with collaboration between the OPO CEO, OPO Clinical Director, and faculty from the university RC program. Table 1 displays the combined OPO and university RC department's student internship learning objectives.

An agreement was made to facilitate one 160-h OPO internship in 2017. Three RC student interns participated in 2019. The internship was not offered in 2018 due to lack of student interest. Students are given the opportunity to complete their internship during their winter break or during the spring semester of the senior year. The spring semester RC courses are held on Wednesdays, thus allowing students to conduct their internships on any other day. Prior to starting the OPO internship, students received an on-campus orientation to the specialization internship course syllabus. The RC interns were then required to meet with the OPO Clinical Director at the OPO office to complete a nondisclosure agreement drafted by the OPO, interview with the OPO staff, and participate in the OPO formalized per diem ORC model. Orientation consisted of 3 days of intensive in-office didactic training, followed by several full days spent rounding at local hospitals with OPO staff. Becasue of the on-call nature of the OPO schedule, a set schedule for the student's internship could not be created. The student interns were notified of organ donor cases by the OPO and directed to the specific hospital to join the case. The students were limited to $12 \mathrm{~h}$ of work for a single day with a maximum of $32 \mathrm{~h}$ per week.

During the internship, student interns participated in rounds at local hospitals and during organ recovery cases. While rounding, the student interns were responsible for performing chart reviews of patients meeting the OPO organ donor referral criteria and communicating with the hospital staff regarding referred patients. The student interns also observed the determination of brain death for referred patients with the on-call ORC. It was decided to not have student interns be present during the approach of family for consent for organ donation due to the sensitive nature of the consent process. However, following consent, the student interns were present during medical management of the organ donor in the critical care unit, allocation of organs, and during the recovery of organs in the operating room under supervision of the ORC preceptors. RC interns participated in the ordering and interpretation of lab tests and diagnostic testing for organ function, adjustment of ventilator settings, lung recruitment, communication with transplant coordinators and assisted in the operating room by preparing sterile slush for transport of recovered organs while maintaining sterile fields. These tasks correspond to the learning objectives described in Table 1 .

\section{Exploration of intern experiences}

A requirement of the specialization internship was for students to write a weekly narrative reflective journal about their experiences during the internship. These reflective journals were analyzed qualitatively to explore their combined experiences during the internship. When writing the reflective journals, students were asked to describe their experiences using the following sections: (i) weekly activities; (ii) recommendations for changes/additions/discontinuation in therapy; (iii) supervision; (iv) training; (v) learning (vi) ethics; (vii) satisfaction; and (viii) critical incidents. Institutional Review Board approval was obtained from TXST to retrospectively analyze the student reflective journals. When analyzing the reflective journals, the five-phased cycle of qualitative analysis described by Yin [5] were followed: compiling, disassembling, reassembling, interpreting, and concluding.

The compiling phase involved the download of submitted narrative reflective journals the students submitted. During the disassembling phase described by Yin [5], the weekly reflective journals were coded using a grounded theory with open coding approach in which data were used to develop theories and meaning using inductive reasoning [5, 6]. The line-by-line coding technique [7] was used to code data and special attention was given to develop analytic codes rather than descriptive codes as a way to use a higher level of coding while assessing the participant's experiences and remove any investigator bias in the study [6, 7]. To complete the line-by-line coding, line numbers were inserted into the left margin of the reflective internship journal using Microsoft Word. Codes were then hand-written in the right margin of the printed document.

The reassembling phase described by Yin [5] involved the development of a coding typology and the development of tables categorizing the data into matrixes. This allowed various segments of data to be grouped together or compared among each other [7]. To develop the matrixes, Microsoft Word was utilized to create tables and quotes with their corresponding line numbers. These matrixes were then used during the interpreting and concluding phases described by Yin [5].

Throughout this study, trustworthiness and validity of the results were addressed by collaborating evidence through triangulation of multiple data sources [8]. This was achieved by analyzing data from four RC interns and at two different times/years. This study addressed the transferability of the results through the use of rich and dense data and utilizing a systematic approach of data analysis $[8,9]$. Researchers attempted to describe the experiences in the contect of an internship to become more meaningful to the reader. Confirmability was achieved through member checking of the identified themes [8].

TABLE 1

\section{Combined organ procurement organization (OPO) and undergraduate respiratory care program student internship} learning objectives

Upon completion of an OPO internship, a respiratory care student intern should be able to

1. Evaluate and examine all imminent deaths for organ donor potential, using physiological criteria established by the hospital, the governing organizations for donation, and the OPO

2. Perform an in-depth physical, medical and social assessment of Authorized Donors to assess for risk-factors and organ viability including chart review of past medical history, history of present illness, laboratory data, and imaging data

3. Initiation of the OPO's standards of care for organ donor medical management and care of the patient/family/staff until a full-time ORC can arrive on site

4. Educate hospital staff (including physicians, nurses, respiratory therapists, etc.) regarding the specifics of donation including referral criteria, evaluation and management

5. Observe AAN guideline driving brain death determination

6. Facilitate ventilator management and lung recruitment according to the OPO donor management guidelines

7. Draw blood from organ donors for routine laboratory analysis and serological tests and interpret laboratory values

8. Assess hemodynamic status of an organ donor and become familiar with vasopressor administration/titration

9. Identify sterile drapes and avoid sterile fields in the OR while aiding the organ recovery coordinators 


\section{RESULTS}

Initially, one RC student who is also a co-author of this article (AMP), expressed interest in the OPO internship and was selected by the faculty to participate in the internship based on academic performance. The student intern completed the internship during the Spring 2017 semester (January-May 2017). Due to the success of the first OPO internship, three students participated in the internship during 2019 (January-May 2019).

After performing an analysis of the student reflective journals, three major themes were identified: emotional competence, student autonomy, and unpredictability of organ donor cases.

\section{Emotional competence}

Throughout the OPO internship, the RC interns demonstrated a progression of emotional competence. During the beginning of the OPO internship, RC intern B repeatedly described being "overwhelmed," having "information overload," and being "busy" in the reflective journal. However, as the internship progressed, the student's attitude changed and became more comfortable in the role. For example, during week 3, RC intern B was able to help with a phone call and "this made me feel more helpful than before since I was actually doing something." During week 4, RC intern B started using words such as "amazing week" and stated the ORC "allowed me to do the brand-new referral on my own(ish), from speaking to the nurse to the chart digging to find any rule out criteria and all the possible information on the patient." RC intern $\mathrm{C}$ had a similar progression. Initially describing the experience as, "not doing anything without supervision" and "it did seem to be stressful at times, juggling so many things at once; however I like to stay busy. This is a fast-paced and very involved career choice which I believe I would thrive in." RC intern C later described performing tasks without supervision such as reviewing patient charts, entering ORC notes into their computer system and performing "vent checks, vitals, and recording drips and urine output." This demonstrates a change in emotional competence because the intern is working more independently and is mastering the skills taught during the OPO orientation. Throughout the progression of the reflection journals, the RC interns' attitude and confidence improved. For example, towards the end of the reflection journal, $\mathrm{RC}$ intern $\mathrm{B}$ wrote with enthusiasm and passion for the organ procurement profession. For example, the word "fabulous" is used to describe the experience and stated, "I hope in the future that I could be a member of their team." RC intern C stated, "this internship taught me valuable skills such as communication with hospital staff, empathy/respect for patients and their families, and time management." RC intern C started using medical abbreviations for drips (gtts), lab work and medications not typical of a RC students demonstrating a more thorough understanding of the critical care management utilized by ORCs.

\footnotetext{
Autonomy

Each OPO internship provided students with varying levels of autonomy. For example, Respiratory care intern A was able to perform some routine $\mathrm{RC}$ procedures but not all. The RC intern was able to provide treatments and suctioning of artificial airways but was not allowed to resecure the artificial airway and transport patients without assitance. This is because the OPO employees are considered guests within the ICUs and some procedures still need to be performed by the hospital staff. Instead the RC intern took more of an observational role because they were learning how the ORCs order medications, make ventilator changes, coordinate the organ recovery process for transplantation, and draw blood for serologies. RC intern A stated, "The ORC and I spent the day managing the patient, instead of running the ABGs [arterial blood gases] for TOSA like I had the previous week, I was having the staff RT [respiratory therapist] run ABGs for me and getting to adjust the vent to compensate for anything that was outside of normal limits." This demonstrates a leadership role among the healthcare team and an increase in autonomy even if the RC intern is being supervised and working with their preceptor.
}

\section{Unpredictability of organ donor cases}

An identified weakness of the OPO internship is the unpredictability of organ donor case activity. The RC interns' weekly reflective journals describe periods where the student and preceptor were very busy with multiple organ donor cases occurring at the same time throughout their organ donor service area resulting in a staff shortage for the OPO and other times in which there was an absence of organ donor case activity. For example, $\mathrm{RC}$ intern $\mathrm{C}$ participated in 7 organ donor cases, $\mathrm{RC}$ intern B was able to participate in three donor cases, and RC intern D only had the opportunity to participate in a single organ donor case due to lack of donor activity and conflicts with the RC intern's personal employment. During times of high case activity with multiple cases occurring through the OPO's service area, RC interns appeared to be overwhelmed and did not receive adequate instruction from their preceptors.

The ORCs tried their best to teach me as much as they could, a lot of times they did not have time to explain things to me. The ORCs during cases were so overwhelmed with the workload because of high case activity and understaffing issues.-Intern B

In times of low organ donor case activities, $\mathrm{RC}$ interns mostly participated in chart reviews and assessment of organ donor suitability of referred patients.

To complicate the internship schedule, there is an unpredictability regarding when a patient may progress to brain death and if the patient is a suitable candidate for organ donation. RC interns' schedules reflected the on-call nature of the ORC schedule. In some instances, RC interns were not available for an organ donor case due to class or personal employment. For the OPO internship to be successful, active collaborative communication needs to occur between RC interns and the OPO preceptors.

Despite the identified weakness of the OPO internship, evidence was found in three of the reflective journals exhibiting some level of participation for each of the combined OPO and undergraduate RC program student internship learning objectives found in Table 1 . However, due to the low donor case activity experienced by $\mathrm{RC}$ intern $\mathrm{D}$, evidence was not found for each learning objective.

\section{DISCUSSION}

In today's changing health care environment, RC students at TXST are encouraged to seek cross-training into sub-specialty areas. Additional skills increase the marketability of the health care professional and increase options for continuing professional development. Student internships have been described as a "win-win" scenario providing potential benefits to students and employers [1,3]. Student interns gain valuable job experience applying previously learned knowledge to real world scenarios while enhancing communication, developing critical/ analytical thinking, social interaction, leadership, teamwork, and job acquisition skills [10,11]. Through internships, RC students are able to explore the various specialties within the profession and evaluate employers to determine a good fit for employment. Moroz and Zaccagnini [12] described an example of a RC student exploring the speciality area of research as an elective opportunity within a RC program. The RC student was able to learn about the role of respitatory therapists in medical research by completing a 1 -week observership that enhanced the student's experience with mechanical ventilation and demonstrated additional roles for respiratory therapists with the medical field.

Internships have been described to provide many benefits to students. Taylor [13] described the reality shock new graduates experience when entering the workforce. Conflicting standards between the classroom and what is experienced after employment can cause anxiety and negatively impact job satisfaction and performance because graduates, "lose confidence in their preparation for work" (p. 393) [13]. Studies involving student nurses performing internships showed higher job satisfaction and reduced anxiety due to culture shock because these conflicts were experienced before graduation [13]. We discovered similar "shock" from the interns during the orientation days. However, the 
anxiety lessened as the experience progressed. Other benefits to students conducting internships include job offers, career preparation, stronger resumes, professional self-confidence, communication skills, and interviewing skills $[2,10]$.

The opportunity to conduct an internship with the OPO provides $\mathrm{RC}$ students the ability to learn more about critical care medicine and transition to practicing health care professionals. There is a lack of literature regarding this subject regarding RC students; however, nursing student literature describes this transition. Clinical practicums and terminal internships have been described as a bridge between being identified as a nursing student to a practicing health care professional in which the students change intellectually and emotionally $[14,15]$. Nursing students' personal clinical abilities are considered proficient when they can effectively develop a professional attitude, problem solve, interact with patients, and adjust to new situations [15, 16]. Tseng et al. [15] stated nursing clinical practicums facilitate the transition from student nurse to professional health care practitioner by providing a sense of achievement, recognizing their own responsibility and character, and recognizing the meaning and value of life. While Tseng, et al. [15] recognized the stress associated with clinical practicums, the suffering of patients, and the experience of death and dying, they stated the stress experienced during clinical practicums facilitates the development of student endurance and allows students to recognize the importance of family support systems. This process facilitates nursing students' development of a self-identity and increased maturity [17]. RC interns in the OPO internship developed a similar self-identity and maturity as the rotation progressed. There appeared to be a feeling of excitement when the intern was in a leadership role and had a busy day.

Patton et al. [18] described the importance of reflection through journal writing during senior nursing student clinical practicums as a way to increase critical thinking and alleviate stress that occurs during clinical practicums. Clinical practicum journals are described as an "objective and subjective chronicle" (p. 238) allowing students to reflect on their experiences and providing a connection between classroom theory and practice within the clinical setting [18]. Journal writing further allows students to reflect on achievements and mistakes made during their clinical education [18]. It also provides a method for students to express feelings and reactions to situations that occur during their clinical education [18]. Reflective practice has been referred to, "as a process in which practitioners gain skills to identify, name, and change various assumptions and biases in a systematic fashion to increase awareness, competency, and effectiveness" (p. 252) [19]. Cooper and Wieckowski [19] hypothesized that if reflective practice is incorporated early in the students' clinical education, the self-assessment strategy will continue throughout their clinical education.

The OPO internship in conjunction with student reflective journal writing allowed students to gain additional insight into critical care medicine while developing their emotional competence and assisted with the transition to a practicing health care practitioner. An OPO internship presented an opportunity for students to participate in many critical care skills not practiced during a traditional intensive care internship and reinforce knowledge received in the classroom. This type of internship also provides the opportunity for students to develop professionally and obtain autonomy by determining their own ventilator settings, ordering lab work, and performing lung recruitment on organ donors that may not be able to be performed on a regular critical care patient receiving mechanical ventilation. Student interns collaborated with other health care professionals such as nursing, physicians, transplant coordinators, and surgical staff thus facilitating interprofessional education. The opportunity for OPO internships also promotes the profession of RC through the demonstration of skills and knowledge of respiratory therapists, which may lead to enhancing the placement of a respiratory therapist in this evolving role. Furthermore, a student intern has the opportunity to work with the OPO in any hospital in the OPO's designated service area and can experience a wide range of critical care experiences, consisting of urban, rural, teaching, nonteaching, profit, nonprofit, network/system, and independent.

\section{CONCLUSIONS}

Successful RC student internships with OPOs requires careful collaboration and planning between faculty of the university-based $\mathrm{RC}$ program and leadership of the OPO and is not possible without their support. However, once organized, a student internship with the $\mathrm{OPO}$ has the opportunity to provide a learning experience that is unique among other student critical care internships potentially leading to improved knowledge of medical care regarding other organ systems aside from the cardiopulmonary system, communication skills, advanced ventilator skills, and professional self-confidence. The OPO internship met all of the desires we have for specialty internships. The student was able to fully integrate into the daily functions required by the OPO staff and into the function of each hospital attended. The faculty felt very encouraged at the conclusion of the rotation that a new avenue for student interns had been forged.

\section{DISCLOSURES}

\section{Funding}

This study is unfunded and there are no sources of financial support.

\section{Competing interests}

The authors disclose no conflict of interest with this unfunded research project. None of the authors disclose any relationship with industry. All authors have completed the ICMJE uniform disclosure form at www. icmje.org/coi_disclosure.pdf.

\section{Ethical approval}

The Texas State University Institutional Review Board (IRB) considered this project exempt from IRB oversight (6768).

\section{Notification of prior presentation}

A version of this article was presented at the 2018 NATCO Annual Meeting in August 2018.

\section{REFERENCES}

1. Coco M. Internships: a try before you buy arrangement. SAM Adv Manag J 2000;65(Spring):41-7.

2. Weible R. Are universities reaping the available benefits internship programsoffer?JEducBus2010;85:59-63.doi: 10.1080/08832320903252397.

3. Divine RL, Linrud JK, Miller RH, Wilson JH. Required internship programs in marketing: benefits, challenges and determinants of fit. Marketing Educ Rev 2007;17(2):45-52. doi: 10.1080/10528008.2007.11489003.

4. Bachelors of Science in Respiratory Care. Texas State University website. Available at: https://www.health.txstate.edu/rc/courses/BSRCCurriculum-Sequence.html (Accessed March 9, 2021).

5. Yin RK. Analyzing qualitative data, I: compiling, disassembling, and reassembling. In Yin RK, eds. Qualitative research from start to finish. New York, NY: The Guilford Press; 2011. p. 176-204.

6. Gibbs GR. Thematic coding and categorizing. In Flick U, eds. Analyzing qualitative data: the Sage qualitative research kit. 2nd ed. Thousand Oaks, CA: Sage; 2018. p. 53-73.

7. Gibbs GR. Comparative analysis. In Flick U, eds. Analyzing qualitative data: the Sage qualitative research kit. 2nd ed. Thousand Oaks, CA: Sage; 2018. p. 101-26.

8. Creswell JW, Poth CN. Qualitative inquiry and research design: choosing among five approaches. 4th ed. Thousand Oaks, CA: Sage; 2018.

9. Slevin E, Sines D. Enhancing the truthfulness, consistency and transferability of a qualitative study: utilising a manifold of approaches. Nurs Res 2000;7(2):79-97. doi: 10.7748/nr2000.01.7.2.79.c6113.

10. Schambach TP, Dirks J. Student Perceptions of Internship Experiences. In: Proceedings of the International Academy for Information Management Annual Conference: International Conference on Informatics Education Research; Barcelona, Spain: International Academy for Information Management; 2002; Accessed April 1, 2021. https://search.ebscohost.com/login.aspx?direct=true\&db=eric\&AN= ED481733\& site $=$ ehost-live\& scope $=$ site

11. Gault J, Redinton J, Schlager T. Undergraduate business internships and career success: are they related? J Marketing Educ 2000;22(1):45-53. doi: $10.1177 / 0273475300221006$. 
12. Moroz N, Zaccagnini M. The impact of a research elective on a respiratory therapy student's perspective. Can J Respir Ther 2019;55:36-9. doi: 10.29390/cjrt-2019-003.

13. Taylor MS. Effects of college internships on individual participants. J Appl Psychol 1988;73(3):393-401. doi: 10.1037/0021-9010.73.3.393.

14. Kaihlanen A, Haavisto E, Strandell-Laine C, Salminen L. Facilitating the transition from a nursing student to a registered nurse in the final clinical practicum: a scoping literature review. Scand J Caring Sci 2017;32:466-77. doi: 10.1111/scs.12494.

15. Tseng $H$, Wang $H$, Weng W. Nursing students' perceptions toward the nursing profession from clinical practicum in a baccalaureate nursing program - a qualitative study. Kaohsiung J Med Sci 2013;29:161-8. doi: 10.1016/j.kjms.2012.08.027.
16. Lee K, Kim S, Yang, YL. Preliminary study of outcome-based clinical practicum for undergraduate nursing students. Jpn J Nurs Sci 2019;16:145-54. doi: 10.1111/jjns.12222.

17. HsuP,WangH, EngC, YangM.Studentnurses'transformation processduring a clinical practicum in a two-year bachelor's program. Collegian 2018;25:435-40. doi: 10.1016/j.colegn.2017.11.001.

18. Patton JG, Woods S, Agarenzo T, Brubaker C, Metcalf T, Sherrer L. Enhancing the clinical practicum experience through journal writing. J Nurs Educ 1997;36(5):238-40. doi: 10.3928/0148-4834-19970501-11.

19. Cooper LD, Wieckowski AT. A structured approach to reflective practice training in a clinical practicum. Train Educ Prof Psyc 2017;11(4):252-9. doi: 10.1037/tep0000170. 